\title{
Variantes lexicais para mãe de leite nos estados do Amazonas e da Bahia
}

\author{
Lexical variants for mãe de leite in the states of Amazonas and Bahia \\ Adriana Maria de Jesus SOUSA* \\ Universidade Federal da Bahia (UFBA) \\ Marcela Moura Torres PAIM** \\ Universidade Federal da Bahia (UFBA)
}

\begin{abstract}
RESUMO: O artigo apresenta um estudo dialetológico, com ênfase na área semântica-lexical, que focaliza as respostas dadas pelos informantes do Amazonas e da Bahia à questão 128 Quando a mãe não tem leite e outra mulher amamenta a criança, como chamam essa mulher? (COMITÊ NACIONAL, 2001, p. 31) - do questionário semântico-lexical do Projeto Atlas Linguístico do Brasil, objetivando verificar as coincidências e as divergências lexicais entre os informantes e examinar as possíveis motivações para as escolhas lexicais, associadas à história social e à formação étnica da população das cidades estudadas. Fundamenta-se nos pressupostos teóricos e metodológicos da Dialetologia Pluridimensional, conforme Cardoso (2010). O resultado da pesquisa demonstrou a relevância dessa investigação geolinguística para o conhecimento da norma lexical de um espaço geográfico. Além disso, apresentaram-se as formas alternativas usadas pelos diferentes informantes para referir-se às lexias que representam o mesmo conteúdo semântico.
\end{abstract}

PALAVRAS-CHAVE: Variação. Léxico. Amazonas. Bahia. Dialetologia.

\footnotetext{
* Mestra em Língua e Cultura (UFBA-2018). Especialista em Metodologia do Ensino Superior e metodologia da pesquisa e Extensão (UNEB-2006) e graduada em Licenciatura em Letras Vernáculas (UFBA -2002). Especialista em Língua Portuguesa pelo Núcleo de Apoio à pesquisa (NUAPE- 2014). Professora de Língua Portuguesa da rede estadual de ensino da Bahia há quinze anos, com experiência em supervisão e formação de professores de Língua Portuguesa no Projeto ação Gestar na escola, projeto estruturante da Secretária de Educação da Bahia (acompanhamento pedagógico para professores de língua portuguesa do ensino fundamental II) e formação de gestores escolares e coordenadores pedagógicos no Plano de Formação Continuada da Secretária de Educação da Bahia. Tem interesse em pesquisas relacionadas aos seguintes temas: Dialetologia, Sociolinguística, Atlas Linguísticos, Língua Portuguesa e Variação. E-mail: drillevi@ hotmail.com

*** Marcela Moura Torres Paim é graduada em Letras pela UFPE (2001), mestre (2005) e doutora em Letras pela UFBA (2007). Realizou Estágio Pós-doutoral na UEFS (2019). É professora de Língua Portuguesa do Departamento de Letras da UFRPE, atuando na graduação dos cursos de Letras, História e Serviço Social, e no Programa de Pós-Graduação em Língua e Cultura da UFBA. É Diretora Científica do Projeto Atlas Linguístico do Brasil e tem se dedicado aos estudos da Dialetologia e da Sociolinguística. E-mail: marcelamtpaim@yahoo.com.br
} 
ABSTRACT: The article presents a dialectical study, with emphasis in the semantic-lexical area, that focuses the answers given by the informants from Amazonas and Bahia to question 128 - Quando a mãe não tem leite e outra mulher amamenta a criança, como chamam essa mulher? (COMITÊ NACIONAL, 2001, p. 31) - of the lexical semantic questionnaire of the Brazilian Linguistic Atlas Project, aiming to verify the coincidences and lexical divergences between the informants and to examine the possible motivations for the lexical choices, associated with the social history and the ethnic formation of the population of the studied cities. It is based on the theoretical and methodological assumptions of the Pluridimensional Dialectology, according to Cardoso (2010). The result of the research demonstrated the relevance of this geolinguistic investigation to the knowledge of the lexical norm of a geographic space. In addition, the alternative forms used by the different informants were presented to refer to the lexias that represent the same semantic content.

KEYWORDS: Variation. Lexicon. Amazonas. Bahia. Dialectology.

\section{Introdução}

Neste estudo, focalizam-se as respostas dadas à questão 128 do Questionário semântico-lexical do Projeto Atlas Linguístico do Brasil (ALiB), visando a uma comparação dialetológica entre os falares baianos e amazonenses no tocante às escolhas para referir-se à mulher que amamenta a criança que não é sua.

Este artigo é um recorte da dissertação de mestrado intitulada Aspectos do ciclo da vida na Bahia e no Amazonas: a visão do projeto ALiB, na qual foram identificadas as coincidências e as divergências lexicais entre Bahia e Amazonas, reveladas por meio do repertório linguístico dos falantes, a partir dos dados do Projeto ALiB, motivado pela hipótese de que os indivíduos recorrem a situações ligadas à cultura e à história da língua da sua localidade para se referir a itens do mundo biossocial.

Partindo desse princípio, este trabalho buscou identificar o léxico referente à área semântica selecionada nos estados escolhidos, Bahia e Amazonas, a fim de perceber como comunidades linguísticas distintas podem trazer traços de semelhanças e/ou diferenças. 


\section{Reflexões dialetológicas}

A observação das seleções lexicais feitas pelos informantes, pretensão deste artigo, tem sido alvo dos dialetólogos desde que os estudos geolinguísticos começaram a ser desenvolvidos no Brasil. Até 1996, com o nascimento do Projeto ALiB, traça-se, então, a "mentalidade dialetológica" (ROMANO, 2013) com obras que representaram os primeiros avanços da Geolinguística brasileira, sinalizando a ideia do quanto se faz necessário realizar pesquisas nesta área com o fim de conhecer o português do Brasil.

Para Cardoso (2010), a Geolinguística preocupa-se com o reconhecimento das diferenças ou das igualdades que a língua reflete e com o estabelecimento das relações entre as diversas manifestações linguísticas documentadas ou entre elas e a ausência de dados registrados, circunscritos a espaços e realidades pré-fixados.

No panorama dialetológico, o estudo da língua com foco na variação diatópica iniciou-se na segunda metade do século XIX e teve como marco inicial a publicação do Visconde de Pedra Branca sobre o léxico brasileiro constituindo-se, então, a área lexical como a primeira a ser observada como um instrumento de reconhecimento da variação linguística brasileira.

Mesmo tomando como foco a perspectiva diatópica, a Dialetologia, considerada pluridimensional, preocupa-se com os aspectos, tantos os espaciais como os sociais, porquanto os falantes possuem, além de uma localização regional, um espaço social.

No que diz respeito à questão analisada, verifica-se que a mulher que amamenta uma criança alheia, quando a mãe natural está impossibilitada de o fazer, é também conhecida como mãe de leite, geralmente, esse encargo era dado inicialmente às índias mais jovens. Posteriormente, o papel das amas logo foi delegado às escravas negras (às escravas que já tinham filhos), visto que no século XV dava-se uma conotação negativa ao ato da amamentação. Nesse sentido, era uma ação não digna da mulher civilizada ou de uma dama.

Outras denominações atribuídas às mães de leite, no período colonial, eram mãe de aluguel, segunda mãe ou ainda mãe preta. 
Como expõe Carneiro (2007, p. 121), essa prática de amamentação que percorre a história da humanidade perdurou, de maneira oficializada no Brasil, até final do século $\mathrm{XX}$.

As escolhas lexicais que os falantes baianos e amazonenses fazem para referir-se a este conceito interessam à Dialetologia, que possibilita o mapeamento das diferentes situações de uso, com o comportamento dos indivíduos, diante das diversas possibilidades e a compreensão dessa diversidade que lhes é apresentada.

A Dialetologia constitui-se como a disciplina que tem interesse em estudar, na perspectiva dos diferentes níveis de abordagem da língua, os usos de falantes de determinado espaço geográfico, a fim de perceber convergências e divergências, reconhecendo, assim, diferentes áreas dialetais.

Nesse viés seguiu a produção deste artigo, adotando como metodologia os parâmetros da Dialetologia.

\section{Aspectos metodológicos}

O corpus do estudo em questão foi constituído pelas variantes lexicais fornecidas como respostas para a pergunta 128 do questionário semântico-lexical do $\mathrm{ALiB}$ - área semântica referente aos ciclos da vida das localidades da rede de pontos do Projeto ALiB nos dois estados considerados: Amazonas (Manaus, São Gabriel, Tefé, Benjamin Constant, Humaitá) e Bahia (Salvador, Juazeiro, Jeremoabo, Euclides da Cunha, Barra, Irecê, Jacobina, Barreiras, Alagoinhas, Seabra, Itaberaba, Santo Amaro, Santana, Valença, Jequié, Caetité, Carinhanha, Vitória da Conquista, Ilhéus, Itapetinga, Santa Cruz de Cabrália e Caravelas).

Os dados foram apurados por meio das entrevistas realizadas pelos pesquisadores do Projeto $\mathrm{ALiB}$, nas 27 cidades brasileiras que integram a rede de pontos do Projeto nos estados considerados, com oito informantes por capital e quatro por cidade interiorana.

A pesquisa seguiu a metodologia do Projeto ALiB, que se fundamenta nos princípios gerais da Geolinguística contemporânea, priorizando a variação espacial ou diatópica, mas não deixando de considerar as implicações de natureza social. 
Para a execução da pesquisa foram cumpridas as seguintes etapas:

- Levantamento das respostas fornecidas pelos informantes do Projeto ALiB nas localidades do Amazonas e da Bahia para a pergunta selecionada para este estudo. Nessa etapa, foi imprescindível o acesso aos áudios das entrevistas.

- $\quad$ Análise das variantes registradas, focalizando a identificação da norma lexical dos habitantes das localidades (distribuição diatópica) e o exame de possíveis motivações para as escolhas lexicais, associadas à história social e à formação étnica da população das cidades estudadas.

- $\quad$ Apresentação dos fatos linguísticos pesquisados em quadros, gráficos e cartas linguísticas.

- Análise semântico-lexical das designações auferidas, tendo como respaldo as definições fornecidas pelos dicionários consultados e informações fornecidas pelo próprio informante.

\section{Análise dos dados}

A pergunta Quando a mãe não tem leite e outra mulher amamenta a criança, como chamam essa mulher? (COMITÊ NACIONAL, 2001, p. 31) gerou como resultado oito variantes lexicais em um quadro de 99 ocorrências e 10 abstenções. No quadro a seguir, é possível observar a identidade de uso que se verifica entre os dois estados.

Quadro 1- Mãe-de-leite no Amazonas e na Bahia

\begin{tabular}{|c|c|}
\hline \multicolumn{2}{|c|}{ Mãe-de-leite } \\
\hline Amazonas & Bahia \\
\hline Mãe-de-leite & Mãe-de-leite \\
\hline Ama-de-leite & Segunde-deite mãe \\
\hline Segunda mãe & Mãe amamentação \\
\hline Mãe amamentação & \\
\hline Nodriza (nutriza/nutriz) & \\
\hline Mãe por parte de leite & \\
\hline
\end{tabular}




\begin{tabular}{|l|c|}
\hline & Mãe emprestada \\
\hline & Amamentadora \\
\hline
\end{tabular}

Fonte: Banco de dados do Projeto ALiB.

Os 77 registros da lexia mãe-de-leite representam $77 \%$ das respostas válidas, sendo a mais produtiva nos dois estados. A segunda variante mais produtiva é ama-deleite com nove efetivações. Mãe emprestada, nodriza, mãe por parte de leite e amamentadora aparecem cada uma com apenas um registro, configurando cada uma delas $1 \%$ do conjunto de variantes válidas registradas.

Esses dados são apresentados em percentuais no gráfico 1.

Gráfico 1 - Distribuição das designações mais produtivas para designar Quando a mãe não tem leite $e$ outra mulher amamenta a criança, como chamam essa mulher?" na Bahia e no Amazonas.

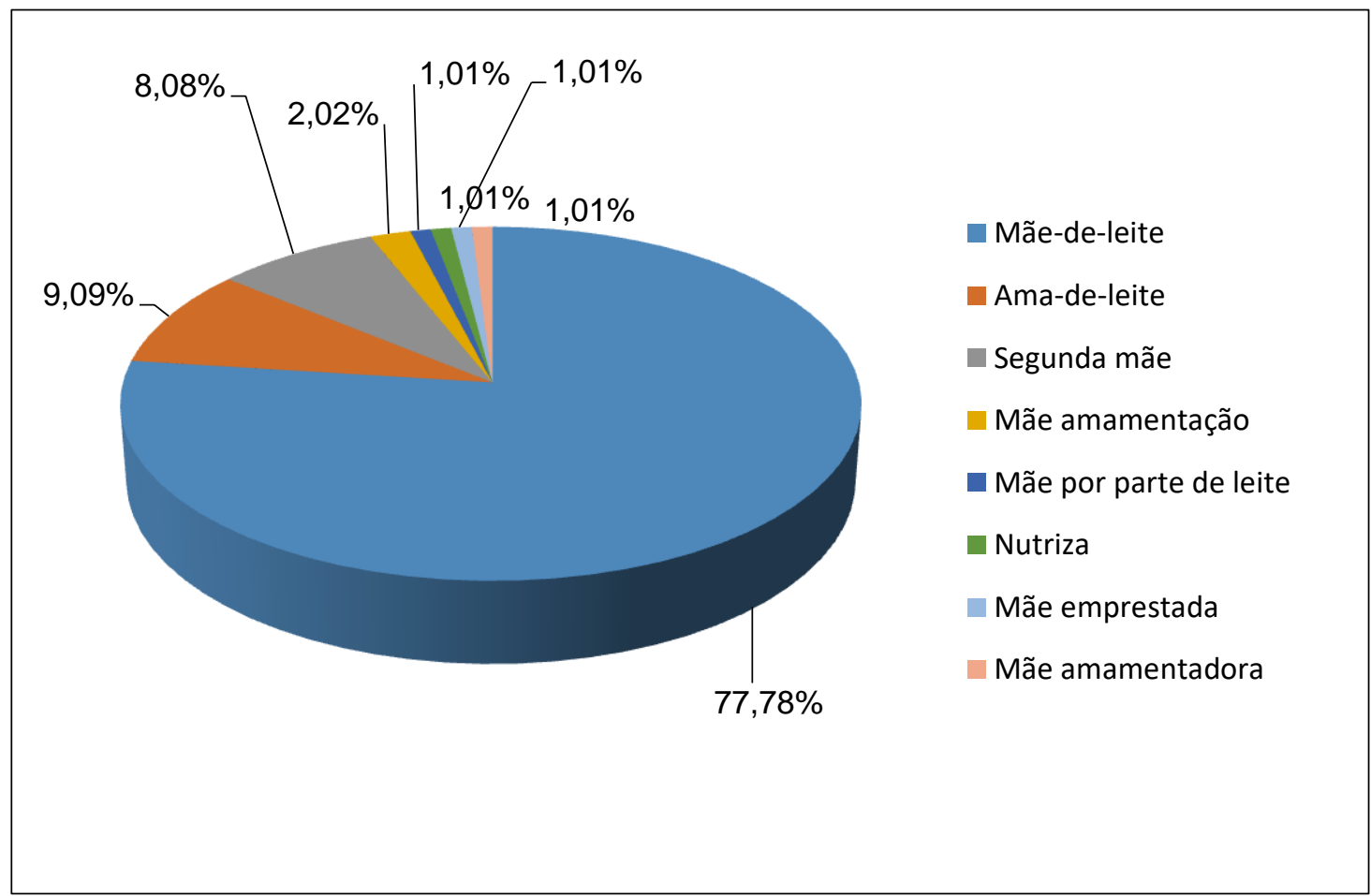

Fonte: Banco de dados do Projeto ALiB.

A distribuição quantitativa nos estados pesquisados se apresenta conforme se ilustra, em percentuais, no gráfico 2. 
Gráfico 2 - Distribuição diatópica das designações mais produtivas para designar "Quando a mãe não tem leite e outra mulher amamenta a criança, como chamam essa mulher?", na Bahia e no Amazonas.

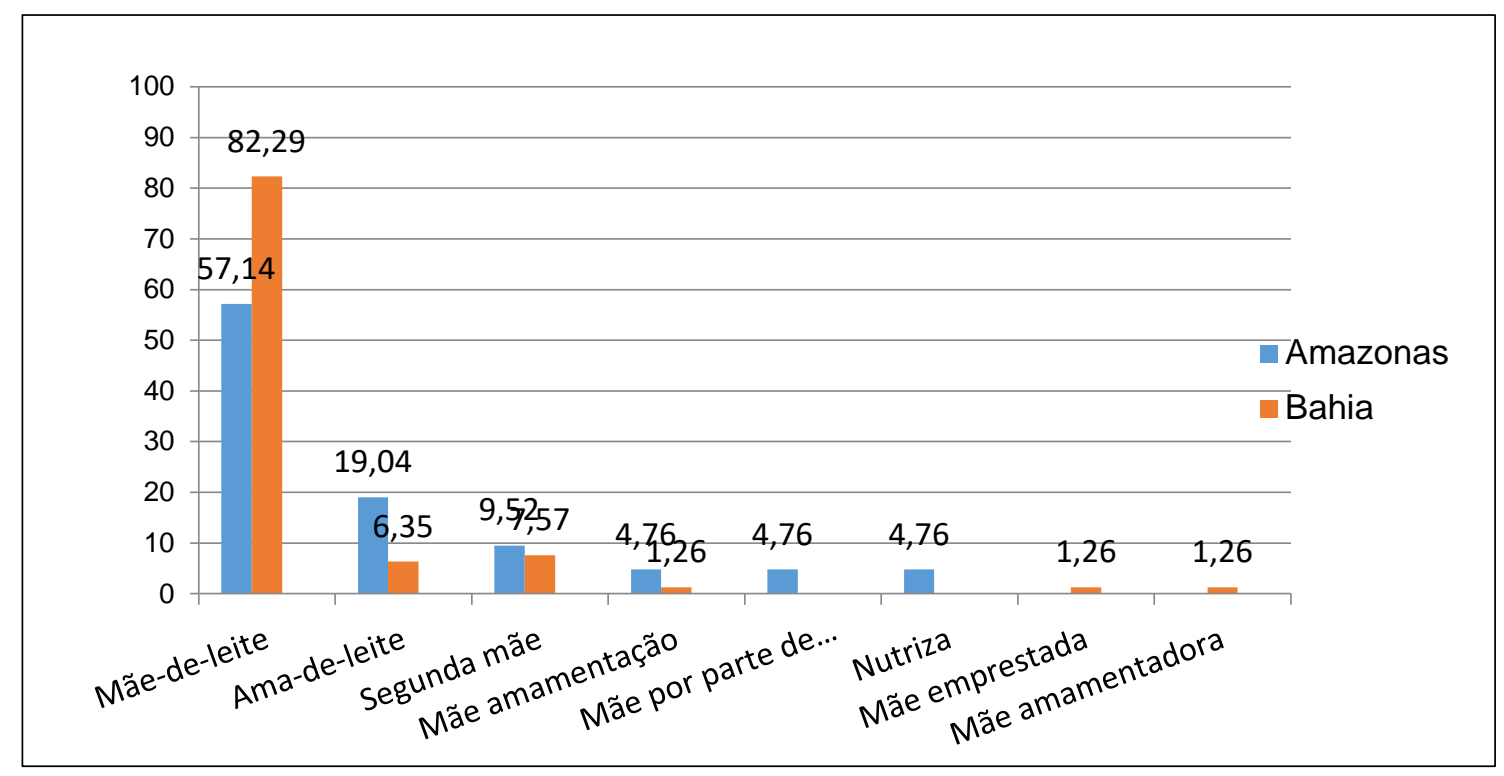

Fonte: Banco de dados do Projeto ALiB.

No quadro 2, é possível visualizar a distribuição diatópica dessas escolhas.

Quadro 2 - Distribuição diatópica das designações mais produtivas para designar " Quando a mãe não tem leite e outra mulher amamenta a criança, como chamam essa mulher?" na Bahia e no Amazonas.

\begin{tabular}{|c|c|c|c|c|}
\hline VARIANTE & BAHIA & AMAZONAS & TOTAL & FREQUENCIA \\
\hline Mãe de leite & 65 & 12 & 77 & $77 \%$ \\
\hline $\begin{array}{c}\text { Ama de leite } \\
\text { Segunda mãe }\end{array}$ & 05 & 04 & 09 & $9 \%$ \\
\hline $\begin{array}{c}\text { Mãe } \\
\text { amamentação }\end{array}$ & 01 & 02 & 08 & $8 \%$ \\
\hline $\begin{array}{c}\text { Mãe por parte } \\
\text { de leite }\end{array}$ & 00 & 01 & 02 & $2 \%$ \\
\hline $\begin{array}{c}\text { Nodriza } \\
\text { (nutriza/nutriz) }\end{array}$ & 00 & 01 & 01 & $1 \%$ \\
\hline
\end{tabular}




\begin{tabular}{|c|c|c|c|c|}
\hline $\begin{array}{c}\text { Mãe } \\
\text { emprestada }\end{array}$ & 01 & 00 & 00 & $1 \%$ \\
\hline Amamentadora & 01 & 00 & 01 & $1 \%$ \\
\hline
\end{tabular}

Fonte: Banco de dados do Projeto ALiB.

O registro dos dados do estado do Amazonas se encontra cartografado na figura 1 , a seguir.

Figura 1 - Denominações para mãe-de-leite no Amazonas

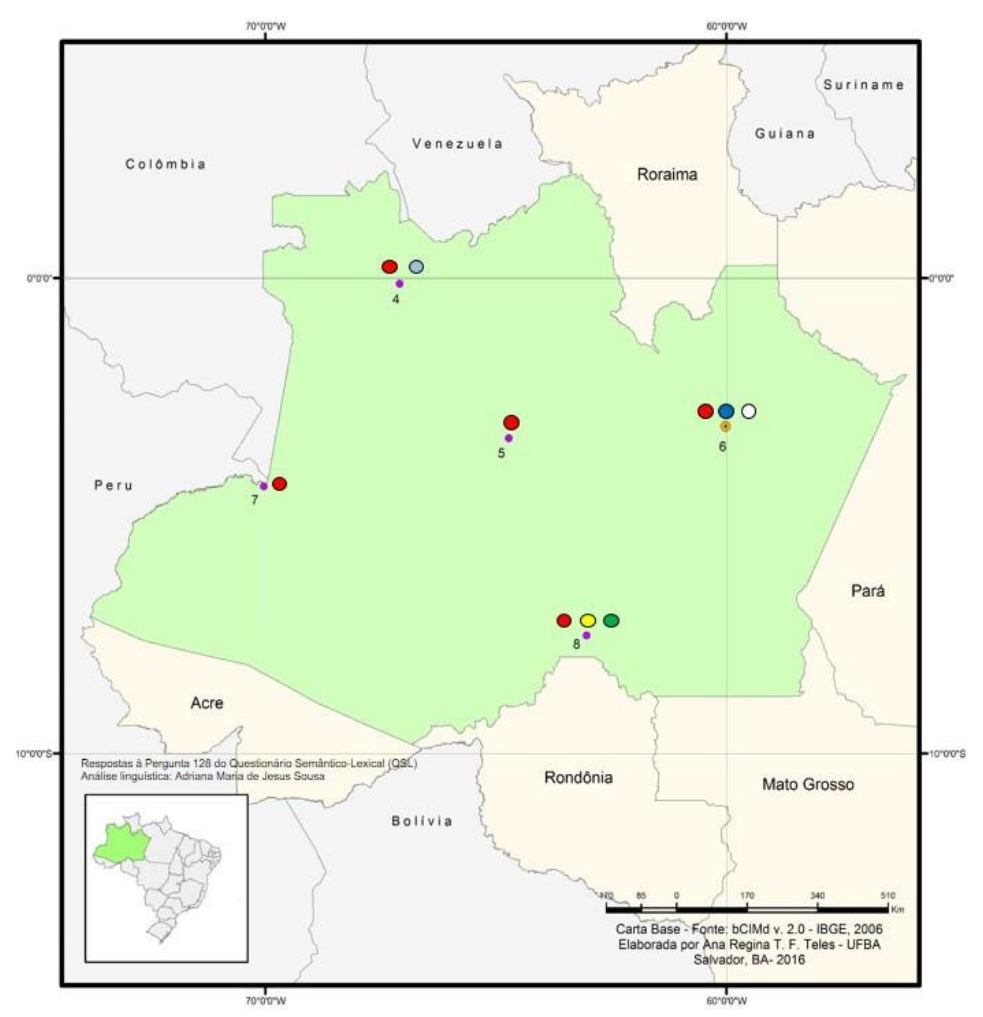

DENOMINAÇÕES PARA

MÃE-DE-LEITE

NO AMAZONAS

Fonte: Banco de dados do Projeto ALiB.

A variante nodriza (nutriza/nutriz), resposta dada por uma informante de São Gabriel da Cachoeira, chama a atenção pela sua origem espanhola. A seguir, apresentase o exemplo com o contexto dessa denominação: 
(1)

INQ- Quando a mãe não tem leite e outra mulher amamenta a criança, como chamam essa mulher?

INF.- Eu sabia, mas agora não sei...minha irmã passou por isso. Teve filhos e não tinha leite. Aí outra mulher deu...

INQ- E essa mulher ficou sendo o quê?

INF- Ficou sendo nodriza. Não é nodriza?

INQ- Este é o que você aprendeu com os médicos. E o que vocês usam aqui, falam em casa?

INF- Pois, eu não sei não.

(São Gabriel da Cachoeira, mulher, faixa II, nível fundamental)

Acredita-se que a escolha é motivada pela influência de determinantes extralinguísticos, como a localização geográfica, o contato com a língua espanhola e a história sociocultural no repertório lexical da população de uma região, visto que São Gabriel da Cachoeira fica situado no extremo noroeste do Brasil. É um dos municípios fronteiriços do país, fazendo divisa com dois países sul-americanos: limita-se ao norte com a Colômbia e a Venezuela.

Os dados do estado da Bahia se encontram cartografados na figura 2:

Figura 2 - Denominações para mãe-de-leite na Bahia

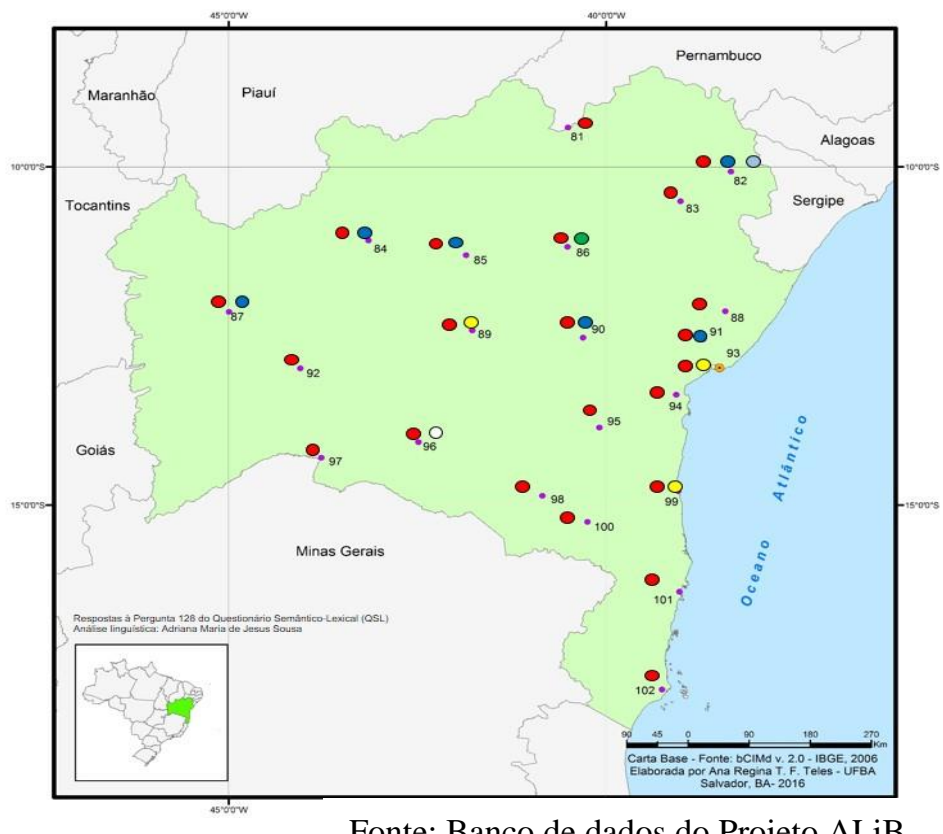

DENOMINAÇÕES PARA MÃE-DE-LEITE NA BAHIA

- Mãe-de-leite

- Segunda mãe

- Ama-de-leite

- Mãe amamentação

○ Mãe emprestada

- Amamentadora

Fonte: Banco de dados do Projeto ALiB. 
No que se refere aos dados da Bahia, é possível perceber que o maior índice dos informantes optou pela denominação mãe-de-leite, a variante está presente em diferentes pontos do território baiano. A segunda forma mais produtiva é segunda mãe, aparecendo em seis diferentes localidades (Jeremoabo, Barra, Irecê, Barreiras, Itaberaba e Santo Amaro). Já ama-de-leite é realizada apenas em três cidades: Salvador, Seabra e Ilhéus.

A partir dos relatos fornecidos pelos sujeitos entrevistados, percebe-se como o léxico funciona também como revelador das marcas históricas e geográficas.

Para tal, foi realizada a pesquisa em três dicionários: Ferreira (1999), Hoauiss (2001) e Michaelis (2009), como expõe o quadro 3:

Quadro 3 - Denominações pesquisadas em dicionários

\begin{tabular}{|c|c|c|c|}
\hline Denominações & Ferreira (1999) & Houaiss (2001) & Weiszflog (2009) \\
\hline Mãe-de-leite & $\mathrm{ND}$ & $\mathrm{D}$ & $\mathrm{ND}$ \\
\hline Ama-de-leite & $\mathrm{D}$ & $\mathrm{D}$ & $\mathrm{D}$ \\
\hline $\begin{array}{c}\text { Segunda mãe } \\
\text { Mãe } \\
\text { amamentação }\end{array}$ & $\mathrm{ND}$ & $\mathrm{ND}$ & $\mathrm{ND}$ \\
\hline $\begin{array}{c}\text { Mãe por parte } \\
\text { de leite }\end{array}$ & $\mathrm{ND}$ & $\mathrm{ND}$ & $\mathrm{ND}$ \\
\hline $\begin{array}{c}\text { Nodriza } \\
\text { (nutriza/nutriz) }\end{array}$ & $\mathrm{D}$ & $\mathrm{D}$ & $\mathrm{ND}$ \\
\hline $\begin{array}{c}\text { Mãe emprestada } \\
\text { Amamentadora }\end{array}$ & $\mathrm{ND}$ & $\mathrm{ND}$ & $\mathrm{D}$ \\
\hline
\end{tabular}

Fonte: Elaborada pelas autoras.

O resultado da investigação das variantes mais recorrentes deve ser considerado, tendo em vista as seguintes legendas: D (dicionarizado), DOS (dicionarizado com outro significado) e ND (não dicionarizado). Do exposto, no que diz respeito à dicionarização 
das lexias, nas obras consultadas, enquanto as denominações ama-de-leite e nutriza estavam registradas nos três dicionários consultados, as variantes segunda mãe, mãe amamentação, mãe por parte de leite e mãe emprestada não foram registradas. Foram encontrados registros para mãe-de-leite em Houaiss (2001) e amamentadora em Houaiss (2001) e Michaellis (2009).

\section{Considerações finais}

Para a questão 128 do questionário semântico-lexical: Quando a mãe não tem leite e outra mulher amamenta a criança, como chamam essa mulher?, os informantes deram como resposta lexias como: mãe por parte de leite, nodriza (nutriza), mãe emprestada, amamentadora e mãe amamentação. As variantes com maior frequência, as mais usadas pelos falantes dos dois estados, foram as denominações: mãe-de-leite $(77,78 \%)$ e ama-de-leite $(9,09 \%)$.

Com a breve análise comparativa aqui empreendida, considera-se que a questão 128 gerou como resultado oito unidades lexicais em um quadro de 99 ocorrências, dentre as quais mãe de leite foi a mais produtiva. Nesse item, não foi possível perceber divergências de caráter diatópico, haja vista as variantes apresentarem registro tanto na Bahia quanto no Amazonas.

No que diz respeito à dicionarização das lexias, foi possível perceber que as denominações unânimes de dicionarização, nas obras consultadas, foram ama-de-leite (segunda variante mais produtiva no Amazonas e terceira na Bahia) e nutriza (forma encontrada no Amazonas).

É possível verificar o fato de a distribuição das variantes ter um caráter mais homogêneo do que heterogêneo, considerando os dados de Salvador e Manaus, bem como de todas as cidades do interior dos dois estados investigados. 


\section{REFERÊNCIAS}

CARNEIRO, M. Uma cartografia das amas-de-leite na sociedade carioca oitocentista. Textos de História. Rio de Janeiro, vol. n. 15)/ n. 1 e 2, p. 121-142. 2007.

CARDOSO, S. O Atlas Linguístico do Brasil: uma visão crítica dos caminhos seguidos e perseguidos. In: II CONGRESSO INTERNACIONAL DE LINGUÍSTICA HISTÓRICA, 1, 2012, São Paulo. Anais... São Paulo: USP. Disponível em: cilh.fflch.usp.br/sites/cilh.fflch.usp.br/files/cad_new.pdf. Acesso em: 01 julho 2019.

CARDOSO, S. Geolinguística: tradição e modernidade. São Paulo: Parábola, 2010.

COMITÊ NACIONAL DO PROJETO ALiB: Atlas Lingüístico do Brasil: Questionários. Londrina: UEL, 2001.

FERREIRA, A. Novo Aurélio Século XXI: o dicionário da língua portuguesa. 3 ed. Totalmente revista e ampliada. Rio de Janeiro: Nova Fronteira, 1999.

HOUAISS, A. Dicionário Houaiss da Língua Portuguesa. Rio de Janeiro: Objetiva. 2001.

ROMANO, V. Balanço crítico da Geolinguística brasileira e a proposição de uma divisão. Entretextos. Londrina, vol. n. 13/n. 2, p. 203-242. 2013.

WEISZFLOG, W. Michaelis: moderno dicionário da língua portuguesa. São Paulo: Companhia Melhoramentos, 2009. 